\title{
Material combination to mitigation of behind armour debris after shaped charge jet attack
}

\begin{abstract}
Marek Szudrowicz ${ }^{1, *}$
${ }^{1}$ Wojskowy Instytut Techniki Pancernej i Samochodowej, 05-070 Sulejówek, Okuniewska 1, Poland

Abstract. When a shaped charge jet perforates the steel armour plate, the residual jet is accompanied by a much wider cloud of behind armour debris (BAD) generated by stress wave interactions. BAD plays an important role in the evaluation of survivability of vehicle crew and components in a vehicle. The Behind Armor Debris (BAD) cloud caused by shaped charge jet impact was investigated. In order to simulate different configuration of material to mitigation of debris cloud the thickness of ceramics target tiles, glass and aramid laminate liners in contact with the armour plates was varied.
\end{abstract}

\section{Introduction}

Armour Piercing Discarding Sabot (APDS) projectiles and High Explosive Anti-Tank (HEAT) warheads are the main weapons used to damage or destroy armoured vehicles. If a such a warhead hits a vehicle, the highest danger for the crew is posed, apart primary jet, by fragments of the primary jet and armour spalls, which may reach a speed $\mathrm{o} 1000 \mathrm{~m} / \mathrm{s}$ in case of heavier fragments and about $3000 \mathrm{~m} / \mathrm{s}$ in case of the lighter ones. Additionally, effects related to changes of temperature and pressure should be considered (Fig. 1) [1].
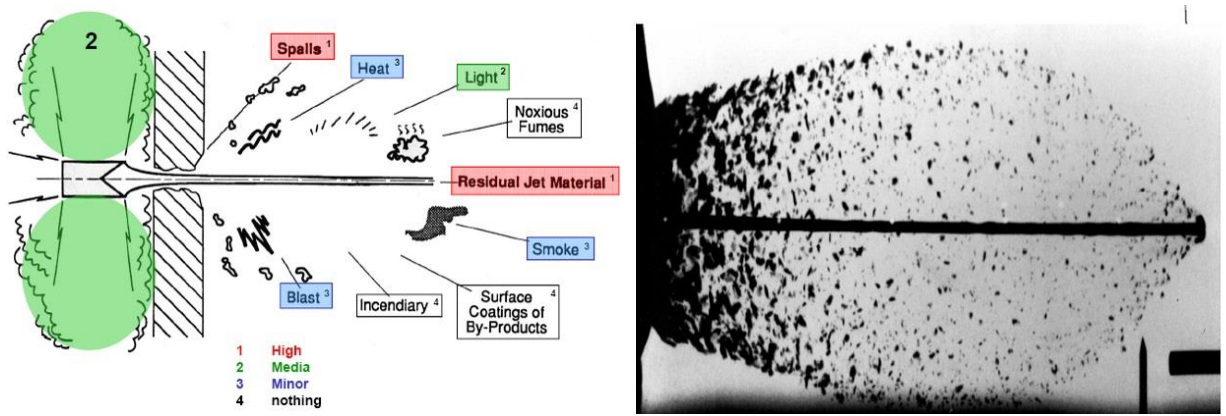

Fig. 1. Effects of the penetration of armour. Behind armour debris.

The following means are employed in design solutions in order to increase the chances of a vehicle crew to survive when vehicle is in danger of being hit by a HEAT warhead:

- detonation of the warhead or otherwise destroying it at some distance from the vehicle,

- disturbing, breaking or fragmenting the shaped charge jet produced after detonation of the warhead,

- reduction of the depth of penetration,

- minimizing of the above-mentioned detrimental effects caused by shaped charge jet penetrating the armour $[2,3,4,5,6,7]$.

Destruction of a warhead, without triggering its detonation by its fuse (without shaped charge jet formation), takes place at some distance from the vehicle using active protection systems, for e.g. that jam the guiding systems or shoot down the projectile, or shortly before

\footnotetext{
*Corresponding author: marek.szudrowicz@witpis.eu
} 
a warhead hits the vehicle, using active systems (that shoot down the projectile) and passive systems (designed to damage or destroy the warhead) [8,9].

If the warhead detonate and a shaped charge jet is formed, appropriate means should be used to make it happen at such a distance from the armour that chances of penetrating it is low. If a detonation of a warhead occurs at a distance exceeding its 6-8 calibres, the probability of penetrating the armour starts to decrease. This means that for e.g. warhead with a calibre of 75-80 mm (PG-7 warheads fired from the RPG-7 launcher) such a distance should be larger than ca. $500 \mathrm{~mm}$.

This method is implemented by the installation of screens, mainly made of horizontally arranged steel bars or rods, or by using net screens. Such a design of screens makes it also possible to destroy the warhead fuse and consequently prevent the shaped charge jet formation. Two mechanisms are mainly used here:

- short-circuit the fuse circuit,

- deforming the warhead conical liner.

These mechanisms operate only when the warhead fuse does not touch any element of the screens structure, i.e. the warhead flies past bars, wires or metal elements of net. At the same time, the distance between adjacent bars or wires and metal elements of the net must be lower that the warhead calibre [11].

The probability of ensuring protection for crews of vehicles is one of the four main parameters that influence selection of a protection system. The other parameters are the level of protection characterized by the type of threat, weight of the system and its costs. For ballistic resistance, in bulletproof tests, the probability of crew protection is calculated mainly as the share of the armoured surface resistant to perforation in the total vehicle surface area. In case of bar or net screens, the probability of protection depends not only on how much of the vehicle surface is covered with such screens but, due to factors determining operation of the mentioned-above warhead-destroying mechanisms, also on their design, i.e. the percentage share of open space in the protection system installed on the vehicle. The open space is the surface for which the fuse of the flying warhead will not touch any part of the structure and a high probability exists that the warhead will be destroyed without generating a shaped charge jet.

In order to improve resistance to shaped charge jet penetration, vehicles are often fitted with additional external armour that often performs also functions related to protection against kinetic projectiles. This group of solutions includes explosive reactive armour (ERA).

Due to its effectiveness in the protection against HEAT warheads, ERA armour is widely used on heavy armoured vehicles $[12,13,14]$. However, installation of such armour brings some negative consequences, e.g. explosion of a reactive cassette affects the vehicle components and may cause injuries to soldiers around the vehicle. Development work on other reactive armour types results in designs free of explosives (Non Explosive Reactive Armour - NERA) but employing inert materials that react to the interaction between the shaped charge jet and the armour using deformable plates that disturb the jet. According to the literature, materials used in such sandwich arrangement are e.g. steel plates and rubber $[15,16,17,18,19]$.

Apart from ERA or NERA armours, group of additional external solutions include space armour structures and composite armours based on ceramics and light layers of metallic or non-woven materials.

If all the above-mentioned means fail and the shaped charge jet perforates the main armour (hull of vehicle), the ultimate protection of the vehicle interior and the crew is the spall-liner installed inside the vehicle. It is employed mainly in order to minimize damage and its installation should result in the complete reduction of the angle of debris cloud $[20,21]$. 
The article presents results of studies with shaped charge carried out using different material combinations designed to reduce the angle of debris cloud with consideration given to selected model solutions of external armour.

\section{Materials and methods}

Interactions between the shaped charge jet and model material combinations were recorded using the SCANDIFLASH XR 450 set with two X-ray sources arranged in mutually perpendicular directions. The tested material was placed between the X-ray sources and film cassettes so that the generated shaped charge jet was perpendicular to the cassettes and parallel to the line running between the X-ray sources and the cassettes (Fig. 2).
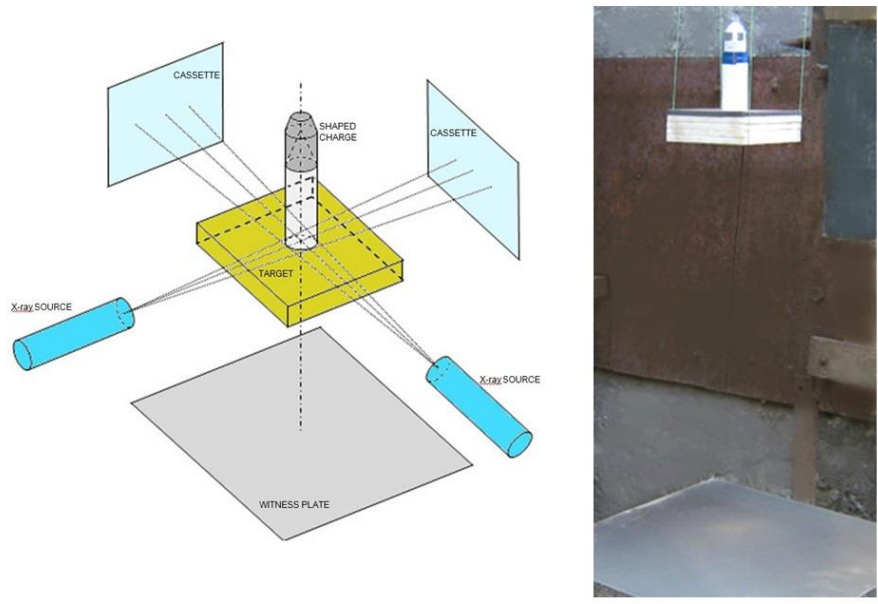

Fig. 2. Schematic view of the test configuration system.

The distance between the upper surface of the tested material combination and the middle of the charge base was adjusted with a PVC tube. During the tests it was $80 \mathrm{~mm}$. Only in the case of testing the influence of distance on jet hitting effects, distance was increase to $160 \mathrm{~mm}$ and $240 \mathrm{~mm}$.

In order to recording results of the jet and its fragments perforating the tested material, a steel witness plate with dimensions of $500 \times 500 \times 1.5 \mathrm{~mm}$ was installed under the sample. Its distance from the lower surface of the tested material was $660 \mathrm{~mm}$. When the charge was detonated alone, without any material, the distance between the witness plate and the lower edge of the charge was $760 \mathrm{~mm}$.

During each test, photographs were taken at different time intervals from triggering the detonation of the shaped charge. This made it possible to determine the speed of the jet. Additionally, consideration was given to the degree of continuity and shape of the jet, distribution of fragments recorded on X-ray photographs and distribution of penetrations in witness plates.

The tested materials were:

- steel armour plate modelling vehicle main armour with thickness of $7 \mathrm{~mm}$, density 7800 $\mathrm{kg} / \mathrm{m}^{3}$, hardness $500 \mathrm{HB}$, yield strength $1450 \mathrm{MPa}$, tensile strength $1700 \mathrm{MPa}$, elongation $7 \%$ - $\mathbf{H H}$

- $\mathrm{Al}_{2} \mathrm{O}_{3}$ ceramic tile with thickness of $10 \mathrm{~mm}$, density $3870 \mathrm{~kg} / \mathrm{m}^{3}$, hardness $1440 \mathrm{HV}$, bending strength $379 \mathrm{MPa}$, modulus $365 \mathrm{GPa}$ - BC

- aramid laminates with thickness of $8,5 \mathrm{~mm}$, density $1100 \mathrm{~kg} / \mathrm{m}^{3}$, tensile strength 300 $\mathrm{MPa}$, modulus $7 \mathrm{GPa}$, elongation $11 \%$ - LA

- glass laminates with thickness of $10,4 \mathrm{~mm}$, density $1960 \mathrm{~kg} / \mathrm{m}^{3}$ tensile strength 485 MPa, modulus $25 \mathrm{GPa}$, elongation $4 \%$ - LG 
- St3 steel plate with thickness of 1,5 mm, rubber core, St3 steel plate with thickness of 1,5 mm - NERA

The study covered the following material combinations:

- steel high hardness armour plate $150 \times 150 \times 7 \mathrm{~mm}$,

- steel high hardness armour plate $150 \times 150 \times 7 \mathrm{~mm}$ with $\mathrm{Al}_{2} \mathrm{O}_{3}$ ceramic tiles with thicknesses of 10, 30, 60 and $90 \mathrm{~mm}$ (arranged as stacks of 100x100x10 mm tiles), ceramic tiles installed on the charge side,

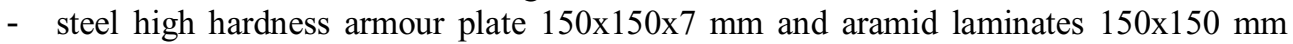
with thicknesses of $8.5,17$ and $25.5 \mathrm{~mm}$ installed behind the armour plate in relation to the charge,

- steel high hardness armour plate $150 \times 150 \times 7 \mathrm{~mm}$ and glass laminates $150 \times 150 \mathrm{~mm}$ with thicknesses of $10.4,20,8$ and $41.6 \mathrm{~mm}$ installed behind the armour plate in relation to the charge,

- steel high hardness armour plate 150x150x7 mm and two glass laminates 150x150 mm with a total thickness of $20.8 \mathrm{~mm}$ installed behind the armour plate at a distance of 20 mm (air gap),

- steel high hardness armour plate 150x150x7 mm and two aramid laminates 150x150 $\mathrm{mm}$ with a total thickness of $17 \mathrm{~mm}$ installed behind the armour plate at a distance of 20 mm (air gap),

- sandwich 100x200 mm combinations: $1.5 \mathrm{~mm}$ thick steel sheet, 3 and $6 \mathrm{~mm}$ thick rubber core, $1.5 \mathrm{~mm}$ steel sheet. Such material combinations were arranged at an angle of $60^{\circ}$ in relation the materials below them, i.e. $20 \mathrm{~mm}$ thick ceramic tiles of $\mathrm{Al}_{2} \mathrm{O}_{3}$, steel high hardness armour plate and laminates: $10.4 \mathrm{~mm}$ thick glass-type and $8.5 \mathrm{~mm}$ thick aramid type.

The study was carried out with shaped charges H-Fe-39-150. The charges were fitted with a conical liner of copper with an angle of $42^{\circ}$ and weight of $37 \mathrm{~g}$. The explosive was RDX. Its weight was $32 \mathrm{~g}$. The charges were prepared for triggering the explosion centrally with a primer. The maximum outer diameter of the liner was $37 \mathrm{~mm}$ and the diameter of the steel casing was $39 \mathrm{~mm}$.

Ability of shaped charge jet to penetration armour plates, confirmed during the preliminary tests on the stack of armour plates is $80 \mathrm{~mm}$.

\section{Results and discussion}

\subsection{Preliminary tests}

In the preliminary test, speed of the shaped charge jet was established on the basis of photographs taken at different time intervals from triggering the shaped charge, as well as there were determined effects made directly on the witness plate by the jet.

The estimated average speed of the shaped charge jet in the air is $7450 \mathrm{~m} / \mathrm{s}$. The witness plate is hit by a dispersed jet. The average angle of flight of fragments is equal to 10.8 degrees. Additionally, a large hole is made as a result of hitting the witness plate by socalled cluster created together with the shaped charge jet (it is part of the charge liner which was not use to create the narrow, long, jet).

Furthermore, studies were carried out on effects accompanying the penetration of a single high hardness armour plate modelling the main armour (vehicle hull), which was used as the reference for other tested materials.

Photographs after the jet penetration in single armour plates show the flight of the plate spalls. Apart from the jet and its fragments, also spalls from the armour plate hit the witness plate (Fig. 3). Large holes in armour plates result from the penetration of the plate with clusters created together with the jet. The average angle of flight of jet fragments and plate spalls is equal to 24.9 degrees. 

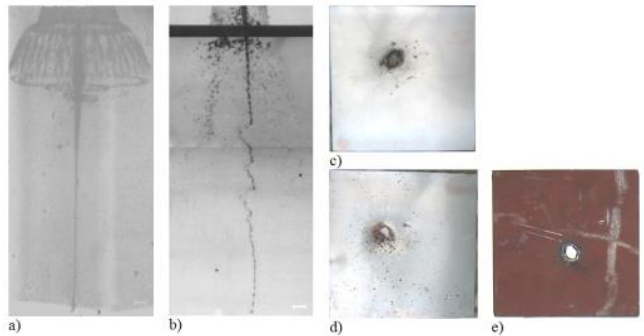

Fig. 3. a) view of a shaped charge jet in air and $b$ ) after the armour plate perforation for $t=60 \mu$ s, c) witness plate $(500 \times 500 \mathrm{~mm})$ after hitting by jet without armour plate and d) after hitting by a jet the armour plate, e) view of perforated armour plate.

\subsection{Tests of materials combinations}

\subsubsection{Studies on penetration of ceramic tiles and the armour plate}

Ceramic tiles were installed on the armour plate. They were used in order to erode the jet and disturb its movement before it reaches the armour plate.

When $10 \mathrm{~mm}$ and $30 \mathrm{~mm}$ thick ceramic tiles were used, the jets shown in the picture (Fig. 4) are disturbed to a degree similar to that observed in the pictures of a jet penetrating an armour plate without ceramic tiles.

The average angles of flight of fragments are equal to 24.7 and 24.5 degrees (Fig. 5).
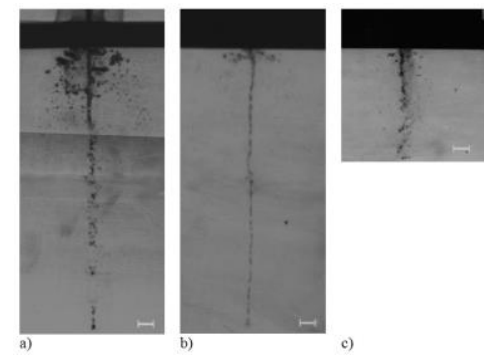

Fig. 4. View of the jet after perforation ceramic armour plate specimens, for ceramic tiles: a) 10 $\mathrm{mm}, \mathrm{t}=60 \mu \mathrm{s}$; b) $30 \mathrm{~mm}, \mathrm{t}=60 \mu \mathrm{s}$;

c) $60 \mathrm{~mm}, \mathrm{t}=90 \mu \mathrm{s}$; d) $90 \mathrm{~mm}, \mathrm{t}=120 \mu \mathrm{s}$.
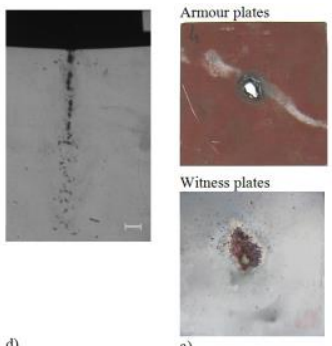

Fig. 5. Comparison of the armour plates $(150 \times 150 \mathrm{~mm})$ and view of the witness plates $(500 \times 500 \mathrm{~mm})$ after perforating by jet the ceramic - armour plate specimens, for ceramic tiles: a) $10 \mathrm{~mm}$; b) $30 \mathrm{~mm}$; c) $60 \mathrm{~mm}$; d) $90 \mathrm{~mm}$.

The estimated jet tip speeds after perforating the ceramic-armour plate specimen are shown in Table 1.

Table 1. The jet speeds after penetrating the ceramic-armour plate specimens.

\begin{tabular}{|c|c|}
\hline Thickness of ceramic $[\mathrm{mm}]$ & Jet speed $[\mathrm{m} / \mathrm{s}]$ \\
\hline 10 & 6,700 \\
\hline 30 & 6,550 \\
\hline 60 & 2,770 \\
\hline 90 & 2,300 \\
\hline
\end{tabular}

The hole after the cluster hitting is only seen for $10 \mathrm{~mm}$ thick ceramic tiles. In case of $60 \mathrm{~mm}$ and $90 \mathrm{~mm}$ thick ceramic tiles, a cloud consisting of jet fragments and plate spalls can be seen in the pictures. The speed of the fragments is still high and the witness plate is perforated. The average angles of flight of jet fragments are equal to 21.8 and 20.6 degrees. The disturbed jet is not so effective anymore in perforating the plate. As can be seen, the jet 
speed and diameter of the hole resulting from the perforation of the armour plate with a shaped charge jet are significantly smaller.

A study was made on how the distance between the shaped charge and the armour plate affects the process of penetration. For the combination of $20 \mathrm{~mm}$ of ceramics with an armour plate, tests were made using a charge located at distances of 160 and $240 \mathrm{~mm}$, which is equivalent to about 5 and 7.5 calibres of the shaped charge. In the course of penetration through this combination of materials, the jet produced at a distance of $160 \mathrm{~mm}$ is still continuous. In case of the charge moved to a distance of $240 \mathrm{~mm}$, after the penetration of the armour plate, the jet is fragmented (Fig. 6). At the same time, the increased distance resulted in the fragmentation of the jet even before it reached the ceramic tiles. In this case holes made in the witness plates are significantly smaller. In the armour plates, not one but several holes were made.

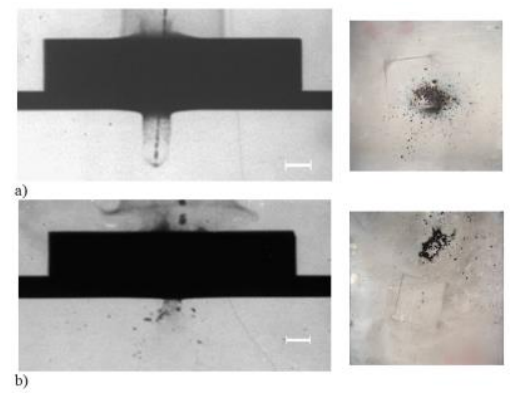

Fig. 6. Photograph of the combination of $20 \mathrm{~mm}$ thick ceramics and an armour plate after it was hit by a jet from a distance of: a) $160 \mathrm{~mm}$ b) $240 \mathrm{~mm}$

\subsubsection{Studies on the penetration of the armour plate with aramid laminate}

The laminate layers were applied mainly in order to stop, as much as possible, spalls from the armour plate. The photographs show that at the initial phase of the penetration, such spalls are stopped by the double or triple layer of aramid laminate. However, for longer time intervals $(\mathrm{t}=90 \mu \mathrm{s})$, the protection offered by the laminate layer is ineffective and the photographs show a cloud of spalls under the laminate. This fact is confirmed by the photographs of the witness plates and dimensions of holes in the aramid laminate (Fig. 7).
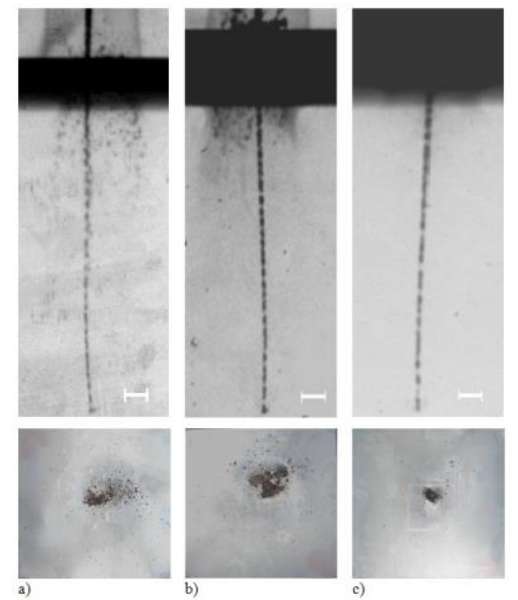

Fig. 7. View of the jet and the witness plates $(500 \times 500 \mathrm{~mm})$ after hitting the armour plate - aramid laminate specimens with: a) single laminate, b) double laminate, c) triple laminate. 
Additionally, it can be shown that aramid laminate layers do not significantly affect the jet head speed as compared to the speeds estimated for the bare armour plate (table 2). However, they reduce the angle of flight of spalls, which has values of $23.9,10.4$, and 8.2 degrees, respectively.

Table 2. The jet speed for the combination of the armour plate with aramid laminates.

\begin{tabular}{|c|c|}
\hline Thickness of aramid laminate $[\mathrm{mm}]$ & Jet speed $[\mathrm{m} / \mathrm{s}]$ \\
\hline 8.5 (1 layer) & 6,740 \\
\hline 17 (2 layers) & 6,250 \\
\hline 25.5 (3 layers) & 7,120 \\
\hline
\end{tabular}

\subsubsection{Studies on penetration of the armour plate combined with glass laminate}

A similar effect was achieved with a glass laminate layer installed under the armour plate (table 3). Additionally it was found out that holes in the witness plates were slightly more scattered than for the same number of aramid laminate layers (Fig. 8). The angle of flight of spalls was equal to $21.4,14.3$, and 11.2 degrees, respectively.

Table 3. The jet speed for the combination of the armour plate with glass laminates.

\begin{tabular}{|c|c|}
\hline Thickness of glass laminate [mm] & Jet speed [m/s] \\
\hline 10.4 (1 layer) & 7,165 \\
\hline 20.8 (2 layers) & 7,240 \\
\hline 31.2 (3 layers) & 6,200 \\
\hline 41.6 (4 layers) & 6,550 \\
\hline
\end{tabular}
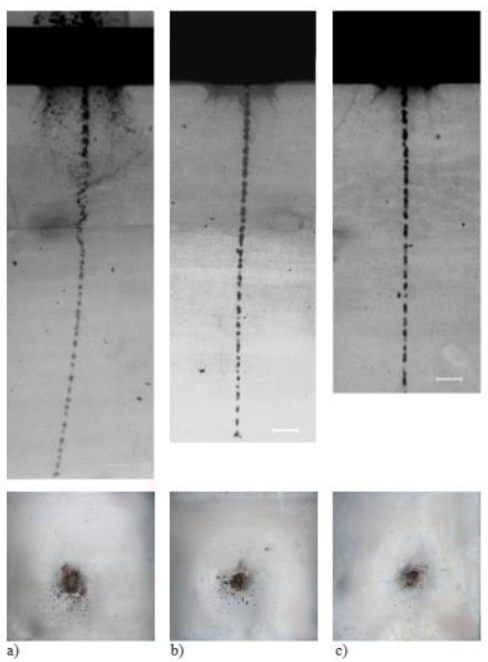

Fig. 8. View of the jet and the witness plates $(500 \times 500 \mathrm{~mm})$ after hitting the armour plate - glass laminate specimens with: a) single laminate, b) double laminate, c) four laminate layers.

Tests were made to find out if an increased distance between the laminate and the armour plate increases the effectiveness of the spall catching effect. Two layers of aramid laminate or two layers of glass laminate were installed at a distance of $20 \mathrm{~mm}$ under the armour plate (air gap). The laminate layers can stop only some part of spalls. The number and arrangement of holes in the witness plate show that in this configuration both laminates offer similar effectiveness in catching fragments (Fig. 9). 

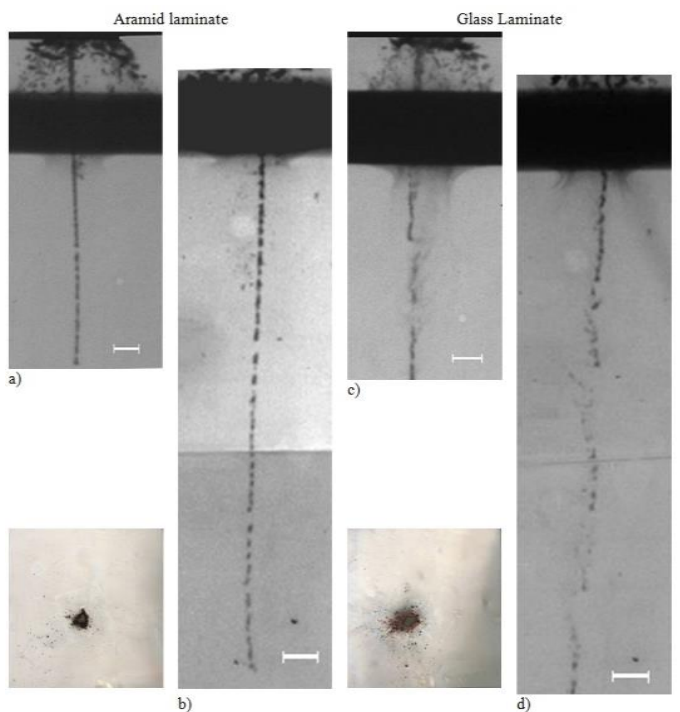

Fig. 9. View of a jet and witness plates $(500 \times 500 \mathrm{~mm})$ after perforation of armour plates $-20 \mathrm{~mm}$ air gap - aramid laminates: a) $t=40 \mu \mathrm{s}, \mathrm{b}$ ) $\mathrm{t}=60 \mu \mathrm{s}$ after perforation of armour plates - $20 \mathrm{~mm}$ air gap glass laminates c) $\mathrm{t}=40 \mu \mathrm{s}, \mathrm{d}) \mathrm{t}=60 \mu \mathrm{s}$

\subsubsection{Studies on penetration of material combinations}

The expectation was that laminates would catch spalls from the armour plate and jet fragments more effectively when the shaped charge jet was disturbed by a ceramic layer before reaching the armour plate. Consequently, the following combination of materials was used: $20 \mathrm{~mm}$ of ceramics - armour plate - $20 \mathrm{~mm}$ air gap - 2 laminates. The analysis of the X-rays shows that the jet maintains its direction (jet fragments continue the flight in the same direction) and the quantity of spalls from the armour plate below the laminate layer is low. The tested configuration is relatively effective in catching the jet fragments and spalls, which is confirmed by the small diameter of the main hole in the witness plate and the low scatter of small spalls (Fig. 10). What draws attention, is the smaller hole in the armour plates. As already established before, this effect is caused by the ceramic tiles.
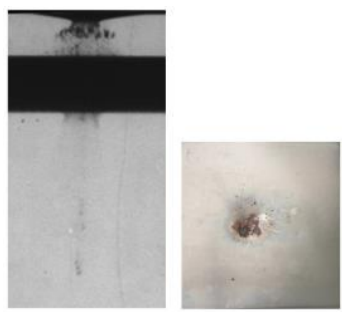

Fig. 10. View of a jet $(\mathrm{t}=60 \mu \mathrm{s})$ and witness plates $(500 \times 500 \mathrm{~mm})$ after perforation of ceramic tiles - armour plate - $20 \mathrm{~mm}$ air gap - glass laminates.

Additionally, studies were made on the reaction of the sandwich type combination steel plate - rubber - steel plate to the shaped charge jet and on how its presence in front of the ceramic tiles affects further penetration. The following combination of materials was chosen: $20 \mathrm{~mm}$ of ceramics - armour plate - 1 glass laminate - 1 aramid laminate (Fig. 11). 

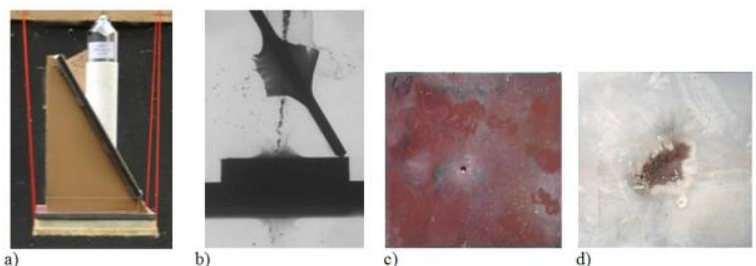

Fig. 11. a) sandwich configuration with a rubber core and ceramics of $20 \mathrm{~mm}$ - armour plate - glass laminate - aramid laminate; b) view of the jet perforating sandwiched materials, c) armour plate $(150 \times 150 \mathrm{~mm})$ and $\mathrm{d})$ witness plate $(500 \times 500 \mathrm{~mm})$ after secimen perforation.

The analysis of the test results shows that the hit of jet head causes violent, local deformation of external sheet metal, which movement disturbs the jet. In one instance of the tests made on thus configured materials, the witness plate was not penetrated. The average angle of flight of jet fragments and spalls is equal to 13, 9.1 and 6.1 degrees.

Graphical summary of the results is shown in figures 12 and 13.

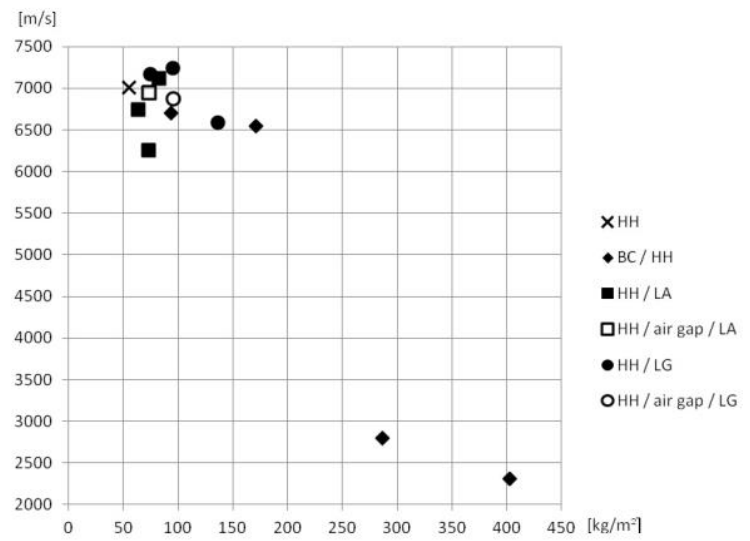

Fig. 12. Influence of material combinations aerial density on the jet speed, after material perforation.

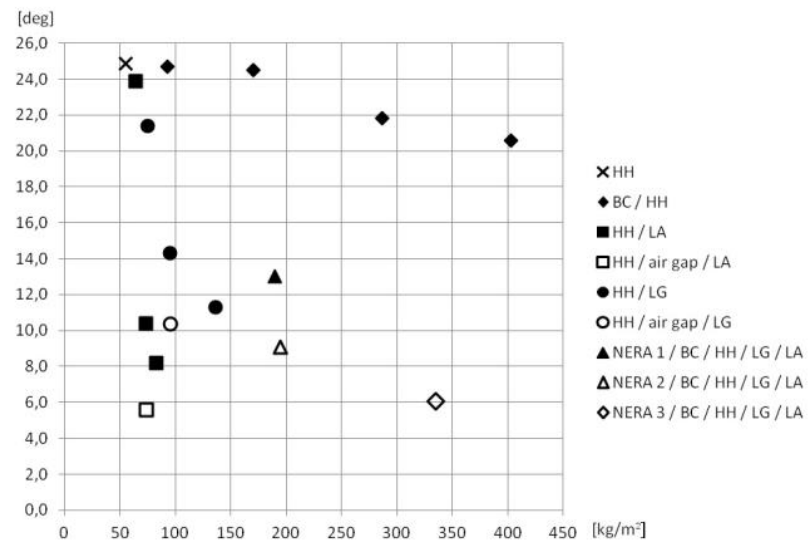

Fig. 13. Influence of material combinations aerial density on the angle of flight of spalls.

\section{Conclusions}

The use of different materials does not cause significant changes in the jet speed after their perforation, in addition to the two cases for thick layers of tiles from in the front of plate armour. The performed studies show that if armour is designed with the principles specified 
in this paper, it is possible to achieve a solution that minimizes both damage made inside the vehicle and probability of sustaining injuries by its crew. According to these principles:

- a HEAT warhead should be forced to detonate at some distance from the main armour, the element that triggers detonation should also disturb the continuity of the jet,

- employed layers that erode the jet and reduce its diameter before it reaches the main armour,

- a spall liner should be installed at some distance behind the main armour, the studies showed that the most effective were aramid laminates

The usefulness of these solutions has been confirmed in the performed studies where, in one case, no perforation of the witness plate was recorded. For this solution, the mass efficiency was calculated.

The mass efficiency was calculated as the ratio of the aerial density of tested material combination to the aerial density of armour plates which protect against perforation over the shaped charge jet. Areal density of materials combination is $335 \mathrm{~kg} / \mathrm{m}^{2}$. In experimental studies it was concluded that the shaped charge jet perforate $80 \mathrm{~mm}$ of armour plates and its areal density is $620 \mathrm{~kg} / \mathrm{m}^{2}$. Therefore, the mass efficiency is equal to the 1,9 .

\section{References}

1. D.R. Kennedy, The History of the Shaped Charge Effect, the First 100 Years, (DTIC, 1983)

2. O.V. Svirsky, N.P. Kovalev, B.A. Klopov, V.V. Ashurov, V.A. Krutyakov, Int. J. Impact Eng., 26, 735 (2001)

3. G.A. Shvetsov, Ballistics '99 $\left(18^{\text {th }}\right.$ International Symposium on Ballistics, San Antonio, Texas, 1999)

4. Z.X. Yin, C.M. Ma, S.X. Li, G.Q. Cheng, Mater. Sci. Eng. A 379, 443 (2004)

5. M. Mayseless, R. Genussov, Int. J. Impact Eng., 23, 585 (1999)

6. V. Madhu, T. Balakrishna Bhat, Defence Sci. J., 61, 394 (2011)

7. A. Sirois, Y. Baillargeon, A. Vallée, G. Bergeron, Technical Report TR 2012-063 (Defence R\&D Canada, Valcartier, 2012)

8. R. Panowicz, M. Konarzewski, J. KONES, 22, 193 (2015)

9. J.D. Powell, D.L. Littlefield, Technical Report ERL-TR-3108 (Ballistic Research Laboratory, Aberdeen Proving Ground, 1990)

10. W.P. Walters, J.A. Zukas, Fundamentals of Shaped Charges (John Wiley \& Sons, New York, 1989)

11. M. Szudrowicz , J. KONES, 18, 639 (2011)

12. H.S. Yadav, B.M. Bohra, G.D. Joshi, S.G. Sundaram and P.V. Kamat, Defence Sci. J. 45, 207 (1995)

13. M. Held, Propellants Explos. Pyrotech, 29, 244 (2004)

14. M. Held, Propellants Explos. Pyrotech, 26, 97 (2001)

15. M. Brand, M Mayseless, R. Genussov, Proceedings - 19th International Symposium on Ballistics (19 ${ }^{\text {th }}$ International Symposium on Ballistics, Interlaken, 2001)

16. K. Thoma, D. Vinkier, J. Kiermeier, U. Deisenroth, W. Fucke, Propellants Explos. Pyrotech, 18, 275 (1993)

17. E. Lidén, A. Helte, A. Tjernberg, Proceedings - 23th International Symposium on Ballistics (23rd International Symposium On Ballistics, Tarragona, 2007)

18. M. Held, Propellants Explos. Pyrotech, 26, 191 (2001)

19. Z. Rosenberg, E. Deckel, Int. J. Impact Eng., 21, 297 (1998)

20. I.Horsfall, Proceedings - 22nd International Symposium on Ballistics (22nd International Symposium on Ballistics, Vancouver, 2005)

21. Report $n r$ FOI-R-1751-SE (FOI Defense Research Agency Weapons and Protection, 2005) 